\title{
Validation for the Children Health Promotion Scale: Development and Psychometric Testing
}

\author{
Min-Li Chen ${ }^{1}$, Li-Na Chou ${ }^{2} \&$ Chun-Huei $\mathrm{Li}^{3}$ \\ 1 Department of Respiratory Care, Graduate Institute of Nursing, Chang Gung University of Science and \\ Technology, Taiwan \\ 2 Department of Nursing, National Tainan Junior College of Nursing, Taiwan \\ ${ }^{3}$ Da-Shiang Elementary School, Taiwan \\ Correspondence: Department of Nursing, National Tainan Junior College of Nursing, No. 78, Min-Tsu Rd. Sec. 2 , \\ Tainan 70043, Taiwan; Tel: 011-886-6-211-0478.
}

Received: May 17, 2017 Accepted: June 2, 2017 Online Published: June 16, 2017

doi:10.5539/gjhs.v9n9p1 URL: https://doi.org/10.5539/gjhs.v9n9p1

\begin{abstract}
Background: Several investigators have developed health promoting lifestyle instruments for adult population. However, few instruments in Taiwan have focused on health-promoting lifestyle measurements from the perspective of children.

Methods: The Children Health Promotion scale (CHP) was developed to focus on health promotion among children. The content validity was supported on the observations of a 6-member panel of experts. Here, based on the responses of 681 Taiwanese children, we examined the construct validity and reliability of the CHP as well as its psychometric properties through factor analysis and reliability measures.
\end{abstract}

Results: The results of Kaiser-Meyer-Olkin (KMO) and Bartlett's sphericity tests indicated that our sample fulfilled the factor analysis criteria. Moreover, the factor analysis yielded a 6-factor instrument, explaining 52.5\% of variance in all 32 items; the 6 factors were myopia prevention, stress management, health maintenance behaviors, nutritional behaviors, physical activities, and basic health-promoting behaviors. The Cronbach's alpha reliability coefficient for the total scale was 0.92 and alpha coefficients for the subscales ranged from 0.71 to 0.85 .

Conclusion: The results of this study indicate that the CHP has satisfactory construct validity and reliability for Taiwanese children. School health providers can therefore use the CHP for children's health promotion efforts.

Keywords: health promotion; healthy lifestyle; instrument development; children

\section{Introduction}

Since the 1960s, health promotion research has increased substantially and has been extended to include individual, family, and community health promotion (Walker, Sechrist, \& Pender, 1987). During the 1980s and early 1990s, research on health promotion increased, and the models of health enhancement were thus proposed (Pender \& Barkauskas, 1992; Walker et al., 1987). This shift toward health promotion was illustrated by Pender and Barkaskas (1992), who described health-promoting behavior as an actualizing tendency "directed toward sustaining or increasing well-being, personal fulfillment, and self-actualization." This perspective has recently been expanded to include contextual or socioecological influences on health promotion.

Research has shown that practicing health promotion behaviors decreases the incidence of disease (Byers, Wick, \& Beard, 2011; Gerçek \& Şen, 2015), and lowers the mortality rate (Silva, 2014). Since 2013, distinguished global health leaders, health ministers, officials, and experts have been gathering in Taiwan to discuss and share insights on crucial worldwide health issues, such as communicable diseases, obesity, ageing, and health inequality (Health Promotion Administration, 2016; 2014a). Although research has long been focused on activities directed toward healthy lifestyle promotion, the special requirements of children's nursing care remain largely underreported. Many Taiwanese children follow unhealthy lifestyle practices, including high-fat diet, high-sugar diet, lack of exercise, physical inactivity (frequent use of televisions, computers, and mobile phones), and chronic exposure to environmental risk factors for vision and dental problems (Health Promotion Administration, 2014a; Lin, Chang, Luh, Hurng, \& Yen, 2014; Liou, Yang, Wang, \& Huang, 2015; Tsai et al., 2015). Reformation of the current status 
is urgently required.

Recent evidence demonstrated that physical activity decreases from the age of school entry (Cheval, Courvoisier, \& Chanal, 2016). Low physical activity is rapidly becoming the social norm in most countries and thus is becoming a critical risk factor for the obesity epidemic. In Taiwan in 2014, the prevalence of overweight and obese children was $34.0 \%$ and $25.0 \%$ for boys and girls respectively (Hsieh, Chen, Huang, Chen, Li, \& Chang, 2014). Obesity also reduces physical activity, thus creating a vicious cycle of increasing body fat levels and declining physical activity. Unhealthy diet and lack of exercise are the main causes of obesity, which in turn is a major risk factor for chronic diseases and causes of several childhood morbidities (World Health Organization, 2016). Children should be encouraged to increase physical activities (Ryan, 2015) and consume various healthy foods by repeatedly and positively exposing them to new foods, by showing them that caregivers and family members enjoy healthy foods, and by limiting their exposure to unhealthy foods (to prevent developing preferences for extremely sweet foods and drinks) (De Lepeleere, De Smet, Verloigne, Cardon, \& De Bourdeaudhuij, 2013; Nybery, Norman, Sundblom, Zeebari, \& Schäfer Elinder, 2016). This will help to facilitate the development of healthy lifestyle habits in from an early age and improve learning ability, mental health, and well-being.

The prevalence of myopia had increased significantly globally. Scholars predict by 2050 there will be 4758 million people with myopia and high myopia (Holden et al., 2016). The incidence of myopia in elementary schoolchildren with aged 10-11 years is $55.53 \%$ in Taiwan (Chang, Wu, Niu, Chen, \& Liao, 2016). The younger that children suffer from myopia, the faster their eyes deteriorate (Cruickshank, Logan, \& Parulekar, 2015; Ohno-Matsui, Lai, Lai, \& Cheung, 2016). Poor vision among schoolchildren has been a persistent main health issue considered by Taiwan's education and health authorities. Since 2010, Taiwan's implementation of its empirical vision care strategy during outdoor school activities has facilitated vision improvement among elementary schoolchildren (Wu, Tsai, Wu, Yang, \& Kuo, 2013). Dental caries is one of the oral diseases in Taiwanese children. The prevalence of dental caries among 5-6-year-olds (79.32\%) in Taiwan (Health Promotion Administration, 2014b) is significantly higher than the global goals for oral health among 5-6-year-olds children ( $\leqq 50 \%)$ (World Health Organization, 2000). To ensure oral hygiene and cleanliness, children should learn the correct methods of brushing teeth; in addition, they should rinse their mouths after meals and brush their teeth in the morning and at night. These activities should be supervised by healthcare providers to provide comprehensive preventive oral health care (Simmer-beck et al., 2011). Parent, family, and social support is associated with health promotion behaviors of schoolchildren (Forthofer, Dowda, Mclver, Pate, \& Barr-Anderson, 2016; Donnelly \& Springer, 2015). Most children have very few opportunities to communicate with supportive adults, their ability to survive the turbulent phases of growing up and ways for protecting their health remain underdeveloped. However, these unhealthy lifestyle risk factors of schoolchildren have not been prioritized in health services of Taiwan.

In the past, public health institutions worldwide have increasingly emphasized the importance of healthy lifestyles. Nurses, particularly school nurses and community-health nurses in primary health care settings, can easily promote healthful habits by assessing the lifestyle patterns of children, intervening to facilitate positive behaviors, and intervening to discourage negative behaviors. Several investigators have developed health promoting lifestyle instruments for adult population (Chen, Chaou, Shiou, Wang, \& Liao, 1996; Walker et al., 1987). However, few instruments in Taiwan have focused on health-promoting lifestyle measurements from the perspective of children, and school nurses in Taiwan lack suitable measurements for assessing the comprehensive health of children. Such instruments could aid in evaluating the success of nursing programs in promoting healthy lifestyle development. This study assessed the psychometric properties of a newly devised Children's Health Promotion scale (CHP) in Taiwanese children.

\section{Methods}

This study was approved by the Institutional Review Board of Chang Gung Hospital in Taiwan (approval number: 101-0617A3). Both the selected children and their parents were oriented on the objectives and procedures of this study, following which they provided written informed consent for participation.

Participants in this study included a representative sample of public and private elementary school students. We employed stratified random sampling according to school districts and different classes for random selection of representative samples. Urban and rural students, ranging from grades 4 to 6 , were recruited from north, central, and south Taiwan.

The CHP was formulated on the basis of the Adolescent Health Promotion scale (AHP) conducted by Chen, Wang, Yang, \& Liou (2003) and a review of literature. With consent from the author, a portion of the items were extracted for use in this study. The CHP was constructed in a 5-point response format to obtain data regarding the frequency of reported behaviors (never, rarely, sometimes, usually, always), with scores ranging from 1 to 5 . The validity of 
the content was assessed by 6 child counseling experts, employed at elementary schools, junior colleges, and universities; these experts included psychologists, health educators, and physicians at school health centers and nursing faculties. All experts were asked to rank the items' priorities, to delete or add information, and to provide an agreement score for each item. All experts rated more than $85 \%$ of the 35 items as "appropriate." On the basis of feedback from the content experts, we made editorial changes to the AHP, deleted some items, and added other items, produce a CHP instrument.

Next, this CHP instrument was tested among 12 children (elementary school students). Chinese Zhuyin phonetic symbols were used in this scale so that schoolchildren could read and understand the questions easily. As our CHP scale was adapted for children 9-12 years of age, hence five non-applicable questions were deleted from the original scale. 'Observe my body at least monthly', 'search for health information', 'search for health information', 'use adequate responses to unreasonable issue', and 'make an effort to choose foods without additives' were removed from the questionnaire. The questionnaire was 35 questions.

\section{Results}

There were 681 participants aged 9-12 years (mean, 11.2 years; median, 11 years). 326 (47.9\%) were female and $355(52.1 \%)$ male. The educational level of $335(49.2 \%)$ of the participants' fathers was grade 12 (high school or vocational level) and that of $86.7 \%$ of the participants' mothers was grade $7-12$. Most participants lived with both their parents $(81.4 \%)$, whereas the other participants had single parents.

\subsection{Content Validity}

To understand the health promotion activities for schoolchildren's health, this scale adopted a structured survey, with a design based on literature reviews, focus group interviews, suggestions of health promotion experts and researchers with school health promotion experience. This research team selected survey items conforming to the aim of this study. The initial questionnaire contained 35 questions, with 5 points for "always: approximately $90 \%$ of the time, I have done it (81-100\%)," 4 for "frequently: approximately $70 \%$ of the time, I have done it (51-81\%)," 3 for "approximately half: approximately $50 \%$ of the time, I have done it (31-50\%)," 2 for "occasionally: occasionally participate in this behavior, approximately $30 \%$ of the time, I have done it (11-30\%)," and 1 for "never: never participated in this behavior, or less than approximately $10 \%$ of the time, I have done it $(0-10 \%)$." Relatively high scores on the scale represented relatively high levels of success in healthy lifestyle promotion. After the survey had been constructed and piloted, it was administered to 681 third to sixth grade schoolchildren. The Cronbach's alpha of the final scale was 0.92 .

\subsection{Factor Analysis}

Before exploratory analysis, Kaisor-Meyer-Olkin (KMO) and Bartlett's sphericity tests were used to measure the sampling adequacy. The results showed that the KMO measure was 0.92 and the significance of Bartlett's sphericity was $0.000\left(\chi^{2}=8065.88, \mathrm{df}=681, p=0.000\right)$, indicating that the samples met the criteria for factor analysis (Hair, Anderson, Tatham, \& Black, 1998). Principal component factor solution explained a variance of $52.5 \%$ and had eigenvalues of $>1.00$. According to the scree plot (Figure 1), the slope of the curve became emergent at the sixth point, and factors 7-9 only contributed $5 \%$ of the accumulated variance. We eliminated 3 items because they did not load strongly on a single factor; thus, we decided on using a 6 -factor instrument. The remaining 32 items were entered into the factor analysis. All items loaded on the expected factors, and the variance was 0.45 for most items, except for two items with variance $<0.4$ (Table 1). The factor analysis of the resulting 32 -item instrument yielded a 6 -factor solution with an explained variance of $52.49 \%$ (Table 2). 


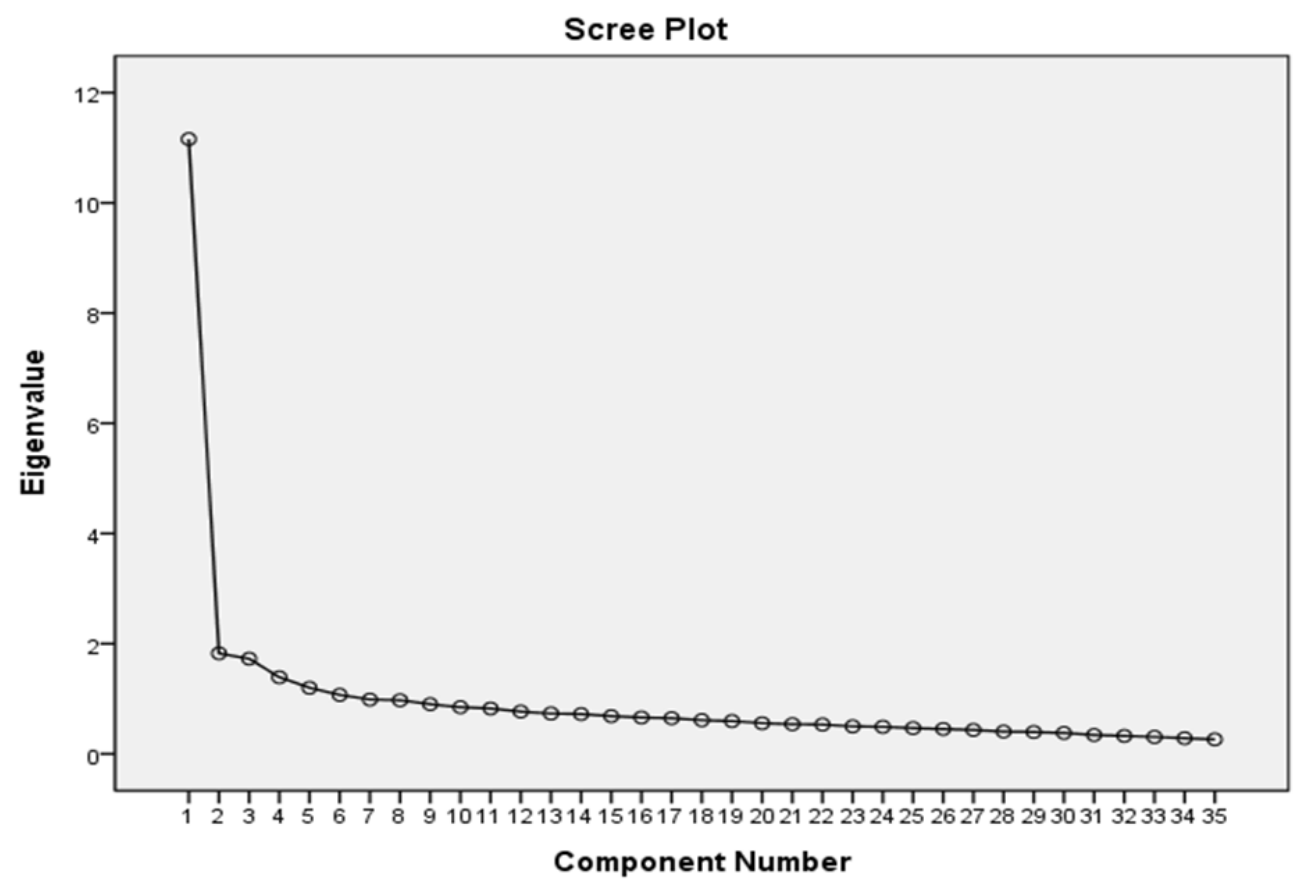

Figure 1 The scree plot

Table 1. Factor loadings and factor structure of the Children Health Promotion scale $(\mathrm{N}=681)$

\begin{tabular}{|c|c|c|c|c|c|c|c|}
\hline & & 1 & 2 & 3 & 4 & 5 & 6 \\
\hline 28. & $\begin{array}{l}\text { When watching television, I take a } 10 \text {-min break for every } 30 \mathrm{~min} \text { of } \\
\text { television. }\end{array}$ & 0.89 & & & & & \\
\hline 29. & $\begin{array}{l}\text { When using computers and cellphones, I take a 10-min break for every } 30 \\
\text { min of use. }\end{array}$ & 0.78 & & & & & \\
\hline 27. & When reading or writing diligently, I take a break for 10 min every $30 \mathrm{~min}$. & 0.75 & & & & & \\
\hline 32. & $\begin{array}{l}\text { During the day, I don't strain my eyes by looking at a computer, television, } \\
\text { or cellphone screen for longer than } 1 \mathrm{~h} \text {. }\end{array}$ & 0.73 & & & & & \\
\hline 30. & $\begin{array}{l}\text { I quietly sit down and rest my eyes, away from any harmful light or glowing } \\
\text { screens for some time. }\end{array}$ & 0.64 & & & & & \\
\hline 26. & $\begin{array}{l}\text { When writing, I maintain a distance of approximately } 35 \mathrm{~cm} \text { between my } \\
\text { eyes and the book. }\end{array}$ & 0.63 & & & & & \\
\hline 31. & I watch television or use computers in well-lit rooms. & 0.43 & & & & & \\
\hline 34. & I wear a hat when I perform outdoor activities. & 0.40 & & & & & \\
\hline 8. & I talk about my concerns with others. & & 0.88 & & & & \\
\hline 10. & I talk about my troubles with others. & & 0.87 & & & & \\
\hline 23. & Every time I am depressed, I try to find the reason for that feeling. & & 0.56 & & & & \\
\hline 9. & I laugh or smile every day. & & 0.53 & & & & \\
\hline 7. & When I have concerns, I contact healthy persons on my own initiative. & & 0.51 & & & & \\
\hline 15. & I appreciate myself. & & 0.50 & & & & \\
\hline 12. & After a meal, I brush and floss my teeth. & & & 0.76 & & & \\
\hline 17. & It is somewhat depressing to me to recognize that my life will end. & & & 0.67 & & & \\
\hline 13. & I wash my hands before each meal. & & & 0.65 & & & \\
\hline
\end{tabular}


11. I obey laws when I buy consumable items 0.60

16. I detect and correct all my mistakes.

18. When I am faced with a tough situation, I come up with new ways to handle 0.44 it.

14. I read the newspaper for news concerning health.

25. I adjust my daily timetable to avoid haste.

0.40

20. At least 3 times every week, I exercise enough to break a sweat for at least 20-30 minutes.

21. In addition to physical education classes, I perform other physical activities (such as walking, swimming, and playing ball) weekly.

33. When I go to school, I participate in outdoor activities during breaks. 0.65

19. I commit myself to maintain daily habits of exercise.

3. I consume high-fiber foods (such as whole grains, fruits, and vegetables).

2. I try to eat no greasy and nonoil food every day.

5. I include five food groups in each meal.

6. I eat breakfast daily.

24. I sleep for 6-8 h each night.

1. I eat 3 meals per day at fixed times.

Table 2. Eigenvalues, cumulative percentage of variance explained by six factors on the Children Health Promotion scale $(\mathrm{N}=681)$

\begin{tabular}{lllll}
\hline Factor & Factor label & Eigenvalue & Variance Explained & Cumulative percentage \% \\
\hline 1 & Myopia prevention & 11.16 & 31.88 & 31.88 \\
2 & Stress management & 1.82 & 5.21 & 37.09 \\
3 & Health maintenance behavior & 1.73 & 4.93 & 42.02 \\
4 & Physical activity & 1.39 & 3.97 & 46.00 \\
5 & Nutritional behaviors & 1.23 & 3.42 & 49.43 \\
6 & Basic health promoting behaviors & 1.19 & 3.05 & 52.49 \\
\hline
\end{tabular}

Factor 1, myopia prevention, was the strongest factor-explaining the greatest percentage of variance of the CHP. This factor was loaded with 8 items: when watching television, I take a 10-min break for every 30 min of television; when using computer and cellphones, I take a 10-min break for every $30 \mathrm{~min}$ of use; when reading or writing diligently, I take a break for 10 min every $30 \mathrm{~min}$; During the day, I don't strain my eyes by looking at a computer, television, or cellphone screen for longer than $1 \mathrm{~h}$; I quietly sit down and rest my eyes, away from any harmful light or glowing screens for some time; When writing, I maintain a distance of approximately $35 \mathrm{~cm}$ between my eyes and the book; I watch television or use computers in well-lit rooms; I wear a hat when I perform outdoor activities.

Factor 2 was stress management and included the following 6 items: When I have concerns, I contact healthy persons on my own initiative; I talk about my concerns with others; I laugh or smile every day; I talk about my troubles with others; I appreciate myself; Every time I am depressed, I try to find the reason for that feeling.

Factor 3 was health maintenance behaviors and included the following 8 items: I obey laws when I buy consumable items; After a meal, I brush and floss my teeth; I wash my hands before each meal; I detect and correct all my mistakes; When I am faced with a tough situation, I come up with new ways to handle it; I read the newspaper for news concerning health; I adjust my daily timetable to avoid haste; It is somewhat depressing to me to recognize that my life will end.

Factor 4 is physical activities and included the following 4 items: I commit myself to maintain daily habits of exercise; At least 3 times every week, I exercise enough to break a sweat for at least 20-30 minutes; when I go to school, I participate in outdoor activities during breaks; In addition to physical education classes, I perform other 
physical activities (such as walking, swimming, and playing ball) weekly.

Factor 5 was nutritional behaviors and included the following 3 items: I consume high-fiber foods (such as whole grains, fruits, and vegetables); I try to eat non-greasy and non-oily food every day; I include five food groups in each meal.

Factor 6 contained basic health-promoting behaviors and included the following 3 items: I eat breakfast daily; I sleep for $6-8 \mathrm{~h}$ each night; I eat 3 meals per day at fixed times.

\subsection{Reliability}

Cronbach alpha was calculated as the measure of internal consistency for the final 32-item instrument; the total instrument demonstrated high internal consistency, with an alpha coefficient of 0.92 (Table 3). Alpha coefficients for the 6 subscales were in the range $0.71-0.85$.

Table 3. Internal consistency of the Children Health Promotion scale and its subscale ( $\mathrm{N}=681)$

\begin{tabular}{llll}
\hline Subscale & Items & Item-subscale $r$ & Alpha \\
\hline 1. Myopia prevention & 8 & $0.43-0.88$ & 0.85 \\
2. Stress management & 6 & $0.49-0.88$ & 0.79 \\
3. Health maintenance behavior & 8 & $0.38-0.76$ & 0.81 \\
4. Physical activity & 4 & $0.60-0.86$ & 0.76 \\
5. Nutritional behaviors & 3 & $0.53-0.60$ & 0.72 \\
6.Basic health promoting behaviors & 3 & $0.47-0.69$ & 0.71 \\
\hline Total scale & 32 & & 0.92 \\
\hline
\end{tabular}

\subsection{Scoring}

When the instrument was used as a whole, the possible range of scores was 32-160. The total mean score of the 681 respondents on the CHP was 102 (range, 41-143). Histograms of the distributions of the scores on the total instrument and the 6 subscales were fairly symmetrical within the range of scores used (skewness $=-0.381$, kurtosis $=-0.099$ ).

\section{Discussion}

The original CHP scale contained 35 questions. Three components were extracted through factor analysis. Because their coefficients were less than the absolute value of 0.32 , question numbers 4 (drink at least $1500 \mathrm{~mL}$ of water daily), 22 (perform warm-up exercises before engaging in strenuous exercises), and 35 (make an effort to deal with unreasonable orders) were omitted; finally, only 32 questions were included. In Taiwan, the current health promotion scales analyze elderly, adult, and adolescent populations; however, no health promotion scales suitable for children has been reported thus far. A salient feature of this scale is the addition of Chinese Zhuyin phonetic symbols so that 9-12-year-old children can read and understand the questions.

Because children represent the future, ensuring their healthy growth and development must be a prime concern of all societies. Myopia is the primary threat to children's vision (Holden et al., 2016). Features of this scale were eye health care strategies included 8 protective behaviors (I quietly sit down and rest my eyes, away from any harmful light or glowing screens for some time; when writing, I maintain a distance of approximately $35 \mathrm{~cm}$ between my eyes and the book; etc) to avoid environmental risk factors for myopia during early life (Lyu, Zhang, Gong, Wang, Chen, \& Guo, 2015; Ramamurthy, Yu Lin Chua, Lin Chua, \& Saw, 2015). Health maintenance behaviors should be established in early and middle childhood. Specially, the protective behaviors of dental health in Taiwanese schoolchildren need to be assessed and oral hygiene activities should be educated from school-based child oral hygiene programs and supervised by adults to provide comprehensive preventive oral health care (Lai, Fann, Yen, Chen, Lai, \& Chiu, 2016). The item 'I obey laws when I buy consumable items'. Unfortunately, most markets are overrun with adulterated food items. From an early age, schoolchildren should be encouraged to develop the habit of checking the ingredients and expiry dates of food items before purchasing them. The item 'When I am faced with a tough situation, I come up with new ways to handle it', can encourage schoolchildren to develop a positive outlook starting from an early age.

The results of this study not only make the government and schools more aware of the health protective factors that 
are beneficial for schoolchildren, but they also propose an effective program to rectify the health promotion factors, resulting in an improvement on the healthy lifestyles of schoolchildren in Taiwan. In this study, the CHP measured the concept of health promotion and the health protection behaviors. This result is different from a study by Chen et al. (2003) who developed Adolescence Health Promotion (AHP) for Taiwanese adolescents defined health lifestyles only included the concept of health promoting. The research design and sample in this study had some limitations. Nevertheless, this CHP still focuses only on health promotion and therefore is unsuitable for detecting or identifying risk behaviors in Taiwanese children. This CHP scale focused on assessing physical health promotion. It may be appropriate that the number of mental health promotion questions can be increased in this instrument. Moreover, because the survey was conducted in the form of self-assessment questionnaires, inaccuracies in the results may be present because of young-age-related limitations in the participants (e.g., cognition and seriousness of questionnaire completion). Future researchers may elect to train pilot instructors to offer explanations while the children are completing the questionnaire to increase the accuracy of the survey.

This study supported the content validity of the CHP on the basis of reported studies and judgments of content experts. The instrument appeared to have sufficient validity and reliability for assessing health promotion behaviors of children populations. This CHP is designed to assess culture-specific health promotion of children in Taiwan aged 9-12 years and can be used as a practical guide for schoolchildren health assessment and identification of healthy behaviors for school health providers. Moreover, this instrument is an easy, practical and comprehensive screening tool for school nurses to assess health-promoting lifestyle behaviors of Taiwanese schoolchildren and can be used as an evaluation tool in school health centers for daily health counseling. The strength of this study is its focus on protection behaviors for health promotion. Specific interventions can be developed to promote healthy behaviors to children and to improve their well-being.

\section{Acknowledgements}

This work was supported by a grant from Formosa Plastics Group. The authors wish to express appreciation for this grant. The school children, parents, and teachers are commended for their participation in this study.

\section{Competing Interests Statement}

The authors declare that there is no competing or potential conflict of interest regarding the publication of this paper.

\section{References}

Byers, D. J., Wicks, M. N., \& Beard, T. H. (2011). Depressive symptoms and health promotion behaviors of African-American women who are family caregivers of hemodialysis recipients. Nephrology Nursing Journal, 38(5), 425-431.

Chang, L. C., Wu, P. C., Niu, Y. Z., Chen, M. L., \& Liao, L. L. (2016). Trajectory of myopia prevention in

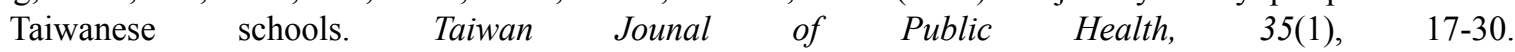
https://doi.org/10.6288/TJPH201635104051

Chen, M. Y., Chaou, C. C., Shiou, H. H., Wang, E. K., \& Liao, C. J. (1996). The development of Chinese version health promoting lifestyle profile. Chang Gung Nursing, 8(1), 14-23.

Chen, M. Y., Wang, E. K., Yang, R. J., \& Liou, Y. M. (2003). Adolescent health promotion scale: development and psychometric testing. Public Health Nursing, 20(2), 104-110. https://doi.org/10.1046/j.1525-1446.2003.20204.x

Cheval, B., Courvoisier, D., \& Chanal, J. (2016). Developmental trajectories of physical activity during elementary school physical education. Preventive Medicine, 87, 170-174. https://doi.org/10.1016/j.ypmed.2016.02.043

Cruickshank, F., Logan, N., \& Parulekar, M. (2015). Associations of high myopia in childhood. Optometry Today, 55(9), 46-50.

De Lepeleere, S., De Smet, A., Verloigne, M., Cardon, G., \& De Bourdeaudhuij, I. (2013). What practices do parents perceive as effective or ineffective in promoting a healthy diet, physical activity, and less sitting in children: parent focus groups. BMC Public Health, 13(1), 1-23. https://doi.org/10.1186/1471-2458-13-1067

Donnelly, R., \& Springer, A. (2015). Parental social support, ethnicity, and energy balance-related behaviors in ethnically diverse, low-income, urban elementary schoolchildren. Journal of Nutrition Education \& Behavior, 47(1), 10-18. https://doi.org/10.1016/j.jneb.2014.06.006

Forthofer, M., Dowda, M., Mclver, K., Pate, R., \& Barr-Anderson, D. (2016). Association between maternal 
support and physical activity among 5th grade students. Maternal \& Child Health Journal, 20(3), 720-729. https://doi.org/10.1007/s10995-015-1873-0

Gerçek, E., \& Şen, H. (2015). Management of gestational diabetes mellitus: self efficacy and perinatal outcomes. Journal of Current Pediatrics, 13(3), 209-215. https://doi.org/10.4274/jcp.44366

Hair, J. F., Anderson, R. E., Tatham, R. L., \& Black, W. C. (1998). Factor analysis. In Hair, J.F.; Anderson, R.E.; Tatham, R.L.; Black, W.C. (Eds.). Multivariate data analysis (5th ed., pp. 87-138.). Englewood Cliffs, NJ: Prentice Hall International, Inc.

Health Promotion Administration, Ministry of Health and Welfare, Taiwan. (2016). The behavioral risk factor surveillance. Retrieved from: http://www.hpa.gov.tw/English/Index.aspx. (18 July 2016)

Health Promotion Administration, Ministry of Health and Welfare, Taiwan. (2014a). Statistical yearbook of health promotion. Retrieved from: http://www.sowf.moi.gov.tw/stat/week/week10403.pdf (10 April 2016)

Health Promotion Administration, Ministry of Health and Welfare, Taiwan. (2014b). The oral risk factor surveillance. Retrieved from: http://www.mohw.gov.tw/MOHW_Upload/doc/oral health_0048302004.pdf (18 June 2016)

Holden, B., Fricke, T. R., Wilson, D. A., Jong, M., Naidoo, K. S., Sankaridurg, P. ... Resnikoff, S. (2016). Global prevalence of myopia and high myopia and temporal trends from 2000 through 2050. Ophthalmology, 123(5), 1036-1042. https://doi.org/10.1016/j.ophtha.2016.01.006

Hsieh, P. L., Chen, M. L., Huang, C. M., Chen, W. C., Li, C. H., \& Chang, L. C. (2014). Physical activity, body mass index, and cardiorespiratory fitness among school children in Taiwan: a cross-sectional study. International Journal of Environment Research and Public Health, 11, 7275-7285. https://doi.org/10.3390/ijerph110707275

Lai, H., Fann, J. C. Y., Yen, A. M. F., Chen, L. S., Lai, M. H., \& Chiu, S. Y. H. (2016). Long-term effectiveness of school-based children oral hygiene program on oral health after 10-year follow-up. Community Dentistry \& Oral Epidemiology, 44(3), 209-215. https://doi.org/10.1111/cdoe.12207

Lin, L. J., Chang, H. Y., Luh, D. L., Hurng, B. S., \& Yen, L. L. (2014). The trajectory and the related physical and social determinants of body mass index in elementary school children: results from the child and adolescent behaviors in long-term evolution study. Journal of Obesity, 1-9. https://doi.org/10.1155/2014/728762

Liou, Y. M., Yang, Y. L., Wang, T. Y., \& Huang, C. M. (2015). School lunch, policy, and environment are determinants for preventing childhood obesity: evidence from a two-year nationwide prospective study. Obesity Research \& Clinical Practice, 9(6), 563-72. https://doi.org/10.1016/j.orcp.2015.02.012

Lyu, Y., Zhang, H., Gong,Y., Wang, D., Chen, T., Guo, X...Kang, M. (2015). Prevalence of and factors associated with myopia in primary school students in the chaoyang District of Beijing, China. Japanese Journal of Opthalmology, 59(6), 421-429. https://doi.org/10.1007/s10384-015-0409-х

Nybery, G., Norman, A., Sundblom, E., Zeebari, Z., \& Schäfer Elinder, L. (2016). Effectiveness of a universal parental support programme to promote health behaviours and prevent overweight and obesity in 6-year-old children in disadvantaged areas, the health school start study II, a cluster-randomised controlled trial. International Journal of Behavioral Nutrition \& Physical Activity, 13, 1-14. https://doi.org/10.1186/s12966-016-0327-4

Ohno-Matsui, K., Lai, T. Y. Y., Lai, C. C., \& Cheung, C. M. G. (2016). Updates of pathologic myopia. Progress in Retinal \& Eye Research, 52, 156-187. https://doi.org/10.1016/j.preteyeres.2015.12.001

Pender, N. J., \& Barkauskas, V. H. (1992). Health promotion and disease prevention: toward excellence in nursing practice and education. Nursing Outlook, 40(3), 106-112.

Ramamurthy, D., Yu Lin Chua, S., Lin Chua S. Y., \& Saw, S. M. (2015). A review of environmental risk factors for myopia during early life, childhood and adolescence. Clinical \& Experimental Optometry, 98(6), 497-506. https://doi.org/10.1111/cxo.12346

Ryan, S. (2015). Can a multi-model training program help to improve physical activity, physical performance, and perceived physical ability in obese children? Journal of Physical Education, Recreation \& Dance, 86, 60. https://doi.org/10.1080/07303084.2015.1009812

Silva, N. (2014). The behavioral risk factor surveillance system. International Journal of Aging and Human Development, 79(4), 336-338. https://doi.org/10.1177/0091415015574184 
Simmer-beck, M., Gadbury-amyot, C. C., Ferris, H., Voelker, M. A., Keselyak, N. T., Eplee, H...Galemore, C. (2011). Extending oral health care services to underserved children through a school-based collaboration: Part 1 - a descriptive overview. Journal of Dental Hygiene, 85(3), 181-192.

Tsai, D. C., Lin, L. J., Huang, N., Hsu, C. C., Chen, S. Y., Chiu, A. W. H., \& Liu, C. J. L. (2015). Study design, rational and methods for a population-based study of myopia in schoolchildren: the myopia investigation study in Taipei. Clinical \& experimental Ophthalmology, 43(7), 612-620. https://doi.org/10.1111/ceo.12532

Walker, S. N., Sechrist, K. R., \& Pender, N. J. (1987). The health-promoting lifestyle profile: development and psychometric characteristics. Nursing $\quad$ Research, $36(2), \quad 76-81$. https://doi.org/10.1097/00006199-198703000-00002

World Health Organization. Childhood Obesity (2016). Retrieved from: http://apps.who.int/iris/bitstream/10665/204176/1/9789241510066_eng.pdf?ua=1\&ua=1 (14 July 2016)

World Health Organization. Oral health information system (2000). Retrieved from:http://www.who.int/oral_health/action/information/surveillance/en/ (1 August 2016)

Wu, P. C., Tsai, C. L., Wu, H. L., Yang, Y. H., \& Kuo, H. K. (2013). Outdoor activity during class recess reduces myopia onset and progression in school children. Ophthalmology, 120(5), 1080-1085. https://doi.org/10.1016/j.ophtha.2013.11.007

\section{Copyrights}

Copyright for this article is retained by the author(s), with first publication rights granted to the journal.

This is an open-access article distributed under the terms and conditions of the Creative Commons Attribution license (http://creativecommons.org/licenses/by/4.0/). 